a few days, I desired her to call in other medical advice if required. Ordered her to continue the oil and lime-water, and some pills, with the third of a grain of opium powder, and two grains of extract of hyoscyamus three or four to be taken daily; with directions that if the bowels became confined, a little castor oil was to be taken every second day.

From Saturday afternoon until Wednesday morning, I examined the urine, and found by the ordinary tests, confirmed by Reincsh's, positive evidences of arsenious acid; but in no case could I detect any trace of lead, which $I$ presume must have been from the almost insoluble character of the chromate.

On my return on the 19 th, the patient mentioned that the day after I had last seen her, she had a return of severe, excruciating pain of the stomach, with tenesmus and frequent bloody stools; but that under the use of the opium pills and mustard applications it gradually subsided. She then expressed herself as being very well, though weakened by her illness. The pulse was down to 80 , soft. The only pathognomonic trace of the late ordeal was found in the tongue, which had the whitish, silvery coating sometimes observable in those who have taken the liquor arsenicalis for some time; but there was very little appearance of the poison in her urine. This woman must have taken at least two scruples of powdered arsenious acid, and the same quantity of the chromate of lead.

In all cases of poisoning with arsenic, I should be inclined to try the light, recently-prepared magnesia again, as it is so easily mixed, and so safe in its administration. In this case not less than eight ounces must have been used within two hours.-London Lancet.

\title{
INJURY TO BOTH EYES BY A POPULAR OINTMENT.
}

BY BENJAMIN BELL, F.R.C.S.E., SURGEON TO THE EYE INFIRMARY.

In the annual report of the Edinburgh Eye Infirmary for 1850, it was mentioned that more than one case had been witnessed of irreparable injury of the cornea, from the use of an ointment much lauded as a remedy for disorders of the eye. This application, on being analyzed by an eminent chemist, was found to contain an immense quantity of acetate of lead, with a large proportion of red precipitate-the former being in crystalline particles large enough to destroy any cornea by mechanical irritation, leaving the latter entirely out of view. I have since met with another case in which the mischief caused by the same ointment was so great, that for some time vision appeared to be irrecoverably lost in both eyes. The patient was a girl of 9 years, who had been suffering from chronic ophthalmia for several weeks, when her mother was persuaded by well-meaning but officious friends to try Porteous's vegetable ointment. Instead of being relieved, the inflammatory symptoms were greatly aggravated, and the child was brought to the Eye Infirmary for advice. Both eyes were extremely vascular, with great intolerance of light, and profuse lachrymation. The right cornea, besides being permeated with red vessels, was dull and bazy, with a few opaque 
patches of a white chalky character. The left cornea was in a still worse condition, almost its entire surface being coated with the same white, earthy-looking deposit. This eye had every appearance of being permanently destroyed; but as the foreign substance was evidently a source of great local irritation, by rubbing against the lining membrane of the lids, it seemed desirable to have it removed. The poor child was, accordingly, put to sleep under chloroform, and the encrustation lifted off like fragments of egg-shell, by means of a curved needle. It adhered so firmly that the subjacent surface bled a little on its removal; but the relief which followed was very marked, and forthwith a gradual process of reparation began, which has proceeded steadily to the present time. The right eye, in which the deposit of foreign matter was less extensive, was treated in the same way, and the improvement has been similar, although less remarkable. There is still more or less obscurity in both corneæ; but she is able to read large print, and her vision will yet continue to improve. I may mention, that after detaching the white deposit, I punctured the cornea in both eyes, so as to evacuate the aqueous humor and relieve the painful tension of the inflamed texture. This procedure, first recommended by $\mathrm{Mr}$. Wardrop many years ago, appears to have fallen into unmerited neglect. My colleague, Dr. Hamilton, and $I$, have seen it singularly advantageous in a number of cases during the past few years; and we cannot remember any in which it was prejudicial. In weakly persons, children especially, who have no blood to spare, when an abscess or penetrating ulcer of the cornea, with or without hypopyon, threatens to destroy the eye, I am acquainted with no remedy so trustworthy as a careful puncture of the cornea. It not only relieves suffering almost at once, but arrests the diseased action and allows the healing process to begin. Chloroform should be employed in most cases, if the child is at all restless. The instrument used for penetrating the cornea ought to be keen, and should enter horizontally, like the knife in extraction of the cataract. It is important, whether we use a knife or a needle, to retract or turn it a little to one side before withdrawing it entirely, so as to secure the complete discharge of the aqueous humor.-Edinburgh Monthly Jour. of Med. Science.

"THE CHANGE OF LIFE" IN WOMEN; WITH REMARKS ON THE PERIODS USUALLY CALLED " CRITICAL."

BY JOSEPH PARRISH, M.D., BURJINGTON, N. J.

I PROPOSE to offer in the present, and subsequent numbers of this Journal, a series of essays upon the subject designated by the above title, to which the candid attention of the profession is invited. It is one, not usually treated of in books to any considerable extent, and, it is feared, not regarded in general practice, in the light which nature and sound views of science would dictate; and as the investigation of it may elicit some novel reflections which are opposed to generally-received notions of the subject, I enter upon it with cautious deference to recognized au- 